\title{
LOS MANUSCRITOS DEL MAR MUERTO Y EL NUEVO TESTAMENTO Los Maestros y las Esperanzas*
}

Hace más de 60 años, en 1947, los beduinos descubrían los primeros rollos de manuscritos en una gruta del acantilado que domina el Mar Muerto cerca de las ruinas de Qumrán. Estos descubrimientos, en los que intervinieron beduinos y excavadores, continuaron hasta 1956. Desde las primeras publicaciones, esos manuscritos atrajeron la atención de investigadores que esperaban encontrar, no sólo información nueva sobre los textos bíblicos y sobre el judaísmo antiguo, sino incluso revelaciones sobre Jesús o sobre el Nuevo Testamento. Esto sucedió justamente después de que la escuela Bultmaniana afirmara que el Jesús histórico escapaba a toda investigación y que se lo debía distinguir del Cristo de la fe. Así, restableciendo la opinión de su mentor E. Renan, para quien "el cristianismo es un esenismo muy exitoso",, A. Dupont-Sommer podía escribir:

El Maestro galileo... aparecía, en muchos aspectos, como una asombrosa reencarnación del Maestro de Justicia. Como éste, predicaba la penitencia, la pobreza, la humildad, el amor al prójimo, la castidad. Como él, prescribió observar la Ley de Moisés, toda la Ley, pero la Ley cumplida, perfecta, gracias a sus propias revelaciones. Como él, fue el Elegido y el Mesías de Dios, -el mesías redentor del mundo. Como él, fue blanco de la hostilidad de los sacerdotes...

* Estas páginas conservan el estilo de la conferencia dada en la Facultad de Teología de la Universidad Católica Argentina, Buenos Aires, en septiembre de 2009. Traducción de Santiago Rostom Maderna. 1894,70

${ }^{1}$ E. Renan, Histoire du peuple d'Israël, Tomo V, libro IX, cap. VII, Lévy - Paris - 
Como él, fue condenado y sufrió el suplicio... Como él, ejerció el juicio sobre Jerusalén que, por haberlo matado, fue tomada y destruida por los romanos. Como él, fundó una iglesia cuyos fieles esperaban con fervor Su glorioso retorno. $^{2}$

Pero Jesús, el Maestro Galileo, que hablaba arameo y enseñaba como los maestros judíos de su tiempo, ¿era un esenio, hasta el punto de ser el Maestro redivivo? Por eso, después de vivas críticas que no se hicieron esperar, Dupont-Sommer matizó ampliamente sus propuestas:

Si ella [la secta esenia] tuvo el privilegio de preparar los caminos, más que cualquier otro movimiento en el judaísmo, la originalidad de la institución cristiana, a pesar de sus afinidades y parecidos que los nuevos textos resaltan, permanece en su conjunto fuera de alcance. ${ }^{3}$

También otros intentaron subrayar, cada uno a su manera, la importancia de los manuscritos: algunos para comprender el Jesús ficticio de los Evangelios como una adaptación del Maestro de Justicia; ${ }^{4}$ otros, dejando de lado los datos básicos, identifican palabras claves gracias a un uso muy particular del género pešer qumranita: Juan Bautista = el Maestro de Justicia, Jesús = el Maestro Impío, Qumrán = Jerusalén, etc. ${ }^{5}$ Otros, para asentar una filosofía o religión New Age volcada al esoterismo, ${ }^{6}$ etc. Finalmente, después de 60 años de investigaciones, ¿qué

2 A. Dupont-SOMmer, Aperçus préliminaires sur les manuscrits de la mer Morte, Maisonneuve - Paris - 1950, 121.

${ }^{3}$ A. DuPONT-SOMmER, Les écrits esséniens découverts près de la mer Morte, Payot Paris - 1959, 24, pero, sin embargo, en 28, escribe: "...el enriquecimiento considerable de la documentación y la evolución de las investigaciones desde 1950, de ninguna manera nos han obligado a abandonar, en algún punto esencial, nuestras primeras opiniones ni a retractar ninguna de nuestras concepciones fundamentales". De todos modos el capítulo Essénisme et Christianisme (381-92) es mucho más matizado.

${ }^{4}$ Por ejemplo J. M. Allegro, The Sacred Mushroom and the Cross: A Study of the Nature and Origins of Christianity Within the Fertility Cults of the Ancient Near East, Hodder and Stoughton - London - 1970; ID., The Dead Sea Scrolls and the Christian Myth, Westbridge Books - Newton Abbot - 1979.

${ }^{5}$ B. ThIERING, Jesus and the Riddle of the Dead Sea Scrolls, Harper Collins - San Francisco - 1992. Pero para J. L. TeICHER, "The Dead Sea Scrolls - Documents of the Jewish-Christian Sect Ebionites", Journal of Jewish Studies 3 (1951) 67-99, Pablo es el Sacerdote Impío y Jesús el Maestro de Justicia. Excepto el Rollo de cobre, las composiciones descubiertas que datan, a más tardar, de la mitad del siglo I a.C. y de las que no quedan más que copias, de ninguna manera pueden remitirnos a personajes del Nuevo Testamento.

${ }^{6}$ Por ejemplo, D. CANnON, Jesus and the Essenes, Huntsville - 1999 y D. MAZIARZ, The Angelic Way to Love: A Manual of Essene Angelology and Personal Growth, Los Angeles - 1995. 
revelaciones guardan estos manuscritos para el nacimiento del cristianismo?

\section{Qumrán y los esenios}

Comencemos recordando brevemente algunos datos importantes. A pesar de algunas voces discordantes, junto a una gran mayoría de estudiosos, considero como segura la identificación del sitio de Qumrán con un establecimiento esenio, como también vinculo las grutas con los habitantes del sitio. ${ }^{7}$ Como lo indica la etimología, los esenios son herederos de los Piadosos -ḥăsîdim (en hebreo) o Asideos, ḥāsînhāsayyāh (en arameo) = essenoi-essaioi (en griego) o esseni (en latín) Esenios- después de la separación de los fariseos en la mitad de siglo II a.C. Son los "santos-hosioi" de Filón, cuyo género de vida se caracterizaba por la búsqueda de santidad. Esto no deja de tener consecuencias en la historia del movimiento y sus creencias. Siguiendo a los asidaioih̆ăsîdim-asideos, de los cuales los libros de los Macabeos han conservado algunos rasgos, eran opositores del helenismo en nombre de su Ley, así como los asideos habían resistido en la guerra santa contra Antíoco IV. Pero jamás se sometieron a la política asmonea, más bien la repudiaron abiertamente bajo Jonatán Macabeo, provocando la separación en dos corrientes religiosas, Esenios y Fariseos, como lo recuerda Flavio Josefo (Antigüedades Judías XIII $\S \S ~ 171-73)$. Cuando tomó el poder sacerdotal en 152, Jonatán parece haber estado en el origen del exilio del sumo sacerdote legítimo cuyo nombre debió ser objeto de una inmediata damnatio memoriae en las listas oficiales del Templo. ${ }^{8}$ Ese sumo sacerdote legítimo, o Maestro auténtico, se exilió en el desierto, con

${ }^{7}$ Ver últimamente E. PUECH, "L'ostracon de Khirbet Qumrân (KhQ 1996/1) et une vente de terrain à Jéricho, témoin de l'occupation essénienne à Qumrân", Flores Florentino: Dead Sea Scrolls and Other Early Jewish Studies in Honour of Florentino García Martínez (ed. A. Hillhorst - E. Puech - E. Tigchelaar), Supplements to the Journal for the Study of Judaism 122, Brill - Leiden - 2007, 1-39. Este ostracon confirma así las antiguas noticias de Plinio el Viejo y Dion Crisóstomo, y el carácter esenio de la biblioteca local, en pleno acuerdo con las conclusiones del excavador R. de Vaux, a pesar de numerosos intentos de cuestionarlo.

${ }^{8}$ Para este tema he dado las indicaciones útiles en "Le grand prêtre Simon (III) fils d'Onias III, le Maître de Justice?", Antikes Judentum und Frühes Christentum. Festschrift für Hartmut Stegemann zum 65. Geburtstag (ed. B. Kollmann - W. Reinbold - A. Steudel), BZNW 97, De Gruyter - Berlin - 1999, 137-58. 
un grupo de sacerdotes y discípulos "para expiar en favor del país y preparar una plantación eterna, un templo santo ..." $(1 \mathrm{QS}[e ́ r e ̀ k]=$ Regla de la Comunidad VIII 1s). Un manuscrito hebreo (4Q523) parece hacer alusión a profanaciones del tesoro del Templo por Jonatán, el sumo sacerdote ilegítimo recientemente designado y aprobado por el seléucida Alejandro Balas. ${ }^{9}$ Cuando se retiró al desierto, este grupo llevó consigo, entre otras cosas, una copia de su patrimonio escrito, y de esta manera preservó sus tradiciones, ritos, costumbres y creencias. Tanto es así, que una parte de la biblioteca descubierta proviene, a menudo por copias interpuestas, del Templo mismo, pero a la cual se agregaron composiciones propias de su nuevo género de vida. De todos modos, con excepción del Rollo de cobre, la literatura descubierta en Qumrán ha sido compuesta, a más tardar, medio siglo antes del nacimiento de Jesús, y la mayoría de las copias son anteriores a la vida pública de Jesús, como lo prueban la paleografía y los tests de Carbono $14 .{ }^{10}$ En consecuencia, no se pueden buscar en ella novedades sobre Jesús. Sin embargo, aunque más antigua, la corriente esenia fue también contemporánea de la predicación de Juan Bautista y de Jesús de Nazaret como de los orígenes cristianos. Se plantea entonces inevitablemente la cuestión de los contactos y vínculos, contactos directos e indirectos. ${ }^{11}$

Se imponen otras dos precisiones. Primero, no se pueden sostener las propuestas de identificación de pasajes del Evangelio de Marcos, de Hechos de los Apóstoles y de las cartas con los papiros de la gruta 7, propuestas que se apoyan sobre desciframientos inadmisibles. ${ }^{12}$ Además,

9 Cf. E. PUECH, Qumrân Grotte 4 XVIII. Textes hébreux (4Q521-4Q528, 4Q5764Q579), DJD XXV, Clarendon Press - Oxford - 1998, 75-83. También los libros de los Macabeos parecen haber conservado indicios de estas intrigas en los presentes en oro que Jonatán Macabeo ofreció a Alejandro Balas, cuando recibió el cargo de Sumo Sacerdote.

${ }^{10}$ Cf. G. BonanI et al., "Radiocarbon Dating of the Dead Sea Scrolls", Atiqot 20 (1991) 27-32, y A. J. T. JULL et al., "Radiocarbon Dating of Scrolls and Linen Fragments from the Judean Desert", Atiqot 28 (1996) 85-91.

${ }^{11}$ Ver últimamente G. J. BROOKE, Qumran and the Jewish Jesus: Reading the New Testament in Light of the Scrolls, Cambridge - 2005, 11, para quien los dos corpora no pueden estar vinculados directamente.

${ }^{12}$ Cf. E. PUECH, "Sept fragments grecs de la Lettre d'Hénoch (1 Hén 100, 103 et 105) dans la grotte 7 de Qumrân (= 7QHéngr)", RdQ 70 (1997) 313-23, muchos fragmentos que esas propuestas atribuyen a libros diferentes del Nuevo Testamento, de hecho pertenecen a junturas del mismo rollo. Ver también E. PUECH, "Note sull'identificazione di 7Q5 con Mc 6,52-53", Ho Theologos 17 (1999) 73-84, y S. Enste, Kein Markustext in Qumran. Eine Untersuchung der These: Qumran-Fragment 7Q5 - 
probar un acuerdo o dependencia no es tarea fácil, dado el estado parcial de la documentación que concierne a los diferentes grupos religiosos de la época. Sólo se pueden aislar los puntos sobre los cuales esenismo y cristianismo se encuentran o se separan cuando se conoce también la posición de otras corrientes, de otra manera no se podrían calificar con precisión las posiciones respectivas de unos en relación con los otros.

En estas líneas yo intentaría destacar algunos parecidos y diferencias principales entre los dos movimientos religiosos, que en un momento fueron contemporáneos. Aunque no fueron escritos por y para cristianos, estos manuscritos conservan su importancia para comprender palabras, expresiones o ideas muy cercanas a pasajes de los evangelios o de otros libros del Nuevo Testamento, sin dejar de lado la exégesis de libros bíblicos, como las relecturas y reinterpretaciones actualizadas en uno y otro corpus, incluso su cumplimiento en la persona de Jesús. Se abordarán entonces rápidamente algunos puntos que tocan la historia de estas dos corrientes religiosas. ${ }^{13}$

\section{La partida hacia el desierto}

\subsection{Juan Bautista y los esenios}

Los evangelios presentan a Juan Bautista principalmente como el que habita en los lugares desiertos hasta el día de su manifestación a Israel (cf. Lc 1,80 y paralelos). Recorría toda la región del Jordán proclamando un bautismo de penitencia para el perdón de los pecados, como está escrito: "una voz grita en el desierto, preparen el camino del Señor..." (Lc 3,2-4). Las proximidades en el espacio, el tiempo y los temas, ¿son suficientes para hacer de Juan un esenio, es decir, un qumranita disidente haciendo discípulos, a quien Jesús le habría pedido el bautismo, como algunos han pretendido?

Mk 6,52-53, NTOA 45, Universitätsverlag/Vandenhoeck \& Ruprecht - Freibourg/Göttingen, 2000. Esta hipótesis, que cada tanto reaparece, debe ser definitivamente abandonada a pesar de autores más amantes de sensacionalismos que del rigor paleográfico.

${ }^{13}$ Como una segunda ala de este abordaje, cf. E. PUECH, "Los manuscritos del Mar Muerto y el Nuevo Testamento. El Nuevo Moisés: algunas prácticas de la Ley", Antiguo Oriente 7 (2009) 219-254. 
Se sabe que la región era recorrida por varios ascetas y movimientos religiosos, ${ }^{14}$ pero nada prueba que Juan haya formado parte de uno de estos grupos, de la comunidad de Qumrán en particular, a la que habría tenido que dejar para fundar su propio movimiento, así como habría tenido que abandonar su corriente de origen: su padre Zacarías, de la clase de Abías, era sacerdote del Templo y su madre era descendiente de Aarón. Sin duda, huérfano a la muerte de sus ancianos padres, habría podido ser adoptado por los qumrano-esenios (ver Flavio Josefo Guerra II $\S 120$ ), pero una situación tan inestable sería sospechosa para el profeta precursor, un nāzîr de su rango. Contrariamente a las inmersiones de los esenios en las piletas rituales -las miqwa'ôt reservadas estrictamente para ellos- tan frecuentes como necesarias para la pureza ritual durante la jornada, sin ministro y sin vínculo directo con el final de los tiempos, Juan practicaba un bautismo único para el perdón de los pecados, del cual él mismo era el ministro, tanto que ese rito le dio el nombre de "Bautista", lo que es único en la historia. ${ }^{15}$ El bautismo de Juan (administrado por él o por sus discípulos) en las aguas vivas del Jordán o en Ainón, que Jesús quiso recibir (distinto del Bautismo en el nombre de Jesús), se dirigía a las multitudes de Jerusalén, de Judea y de la región; no era exclusivo ni pertenecía a un grupo particular, e incluía a los publicanos y los soldados, a los fariseos y los saduceos. No era reiterable porque su eficacia dependía del juicio divino futuro e invitaba a producir frutos de arrepentimiento. Este bautismo era un rito de iniciación con valor escatológico, que preparaba al adepto para la venida inminente del Reino que debe inaugurar el mesías, quien bautizará en el Espíritu y el Fuego.

Aunque adaptados a su nueva situación, los baños rituales esenios, por una parte no se diferenciaban de los practicados en el Templo, y por otra parte, el acceso estaba limitado a los que tenían derecho una vez que el candidato había sido aceptado por el Consejo de la Comunidad o después de la reexaminación del culpable (Regla de la Comunidad = 1QS II 19-III 12, VI-VII). El ritual de entrada en la alianza, que

14 Por ejemplo, Teudas, cf. Hch 5,36, Flavio Josefo, Ant. XX $\S \S$ 97-99; Banus, cf. Hch 21,38 y Flavio Josefo, Guerra II $\S 259$, Ant. XX $\S \S 167-171$, Autobiografía 11, cf. tb. Mt 24,23-27.

15 No era raro en aquella época que los hombres fueran llamados por un sobrenombre, como Judas Iscariote, Simon el Zelote, Judas Macabeo y sus hermanos (1 Mac 2,2-5), etc., pero Juan "el bautista" es único. 
garantizaba la salvación sólo a los que pertenecían al lote de hijos de la luz, se renovaba anualmente por medio de una confesión colectiva, contrariamente al bautismo único de Juan. Se evidencian opuestas dos concepciones diferentes de la espera y de la venida del final de los tiempos. Mientras la comunidad esenia relacionaba con ella misma las promesas de los profetas y se consideraba como el lugar de su primera realización, esperando su culminación escatológica en los días del mesías, Juan prepara directamente la venida, poniendo en guardia contra la irrupción inminente de la cólera de Dios. En Qumrán como en el Antiguo Testamento, el juicio por el Fuego es prerrogativa de Dios; para Juan "aquel que viene después de mí, que es más poderoso que yo, es el que purificará por el Fuego". Juan no hace más que preparar la venida de Aquél que inaugurará los tiempos mesiánicos.

Vestido con un manto de pelos de camello como Elías y bautizando más allá del Jordán para evocar el lugar del arrebato de Elías, los evangelios presentan manifiestamente a Juan como el Elías redivivo anunciado por Malaquías y Ben Sirá, teniendo su bautismo y su misión un valor único (Jn 1,25). Pero la espera del retorno de Elías, transmitida por una tradición que los evangelios atribuyen a los escribas (Mc 9,11 y paralelos), también está presente en los manuscritos de Qumrán que hacen alusión a Malaquías $(3,23)$ en el contexto de la venida del Día de Yahveh, en el manuscrito 4QpapVisions ${ }^{b}$ (4Q558): "Les enviaré a Elías delante [/antes] que...". ${ }^{16} \mathrm{O}$ también a Malaquías $(3,23)$ y a Ben Sirá $(48,10)$ en el manuscrito Apocalipsis mesiánico (=4Q521) 2 iii 1-2: “los padres vuelven hacia los hijos"17 (Lc 1,17). Después siguen la exultación de la tierra a la venida del mesías rey y la aclamación de su cetro. Pero la columna precedente de este último manuscrito presenta una lista de beneficios que Dios mismo llevará a cabo en los días del mesías, lista tomada de Is 35,5-6 y 61,1-2 y del Salmo 146,7-9 (4Q521 2+4 ii 7-8 et 12-13):

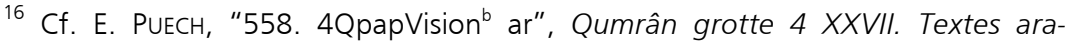
méens, Deuxième partie, DJD XXXVII, Clarendon Press - Oxford - 2009, 215-16.

${ }^{17}$ Cf. E. PUECH, "521. 4QApocalypse messianique", Qumrân grotte 4 XVIII. Textes hébreux (4Q521-4Q528, 4Q576-4Q579), DJD XXV, Clarendon Press - Oxford - 1998, 18-19. 
${ }^{7}$ porque El honrará a los piadosos en un trono de realeza eterna, ${ }^{18}{ }^{8}$ liberando a los prisioneros, devolviendo la vista a los ciegos, enderezando a los encorvados ${ }^{9} \ldots{ }^{12}$ porque El sanará a los heridos de muerte y hará revivir a los muertos, anunciará la buena noticia a los pobres ${ }^{13} y$ colmará a los indigentes, conducirá a los desarraigados y dejará hartos a los hambrientos, ${ }^{14}$ y... ${ }^{19}$

A la pregunta de los discípulos de Juan de parte de su maestro: “¿Eres tú el que debe venir o tenemos que esperar a otro?”, Jesús responde con una secuencia tomada de las mismas fuentes (Mt 11,2-6 y Lc 7,22-23): ${ }^{20}$

... los ciegos ven y los cojos caminan, los leprosos son sanados y los sordos escuchan, los muertos resucitan y la buena nueva es anunciada a los pobres (Mt 11,5).

Pero en los dos grupos, la mención de la resurrección que parece haber sido sacada de Is 26,19 y la de la Buena Noticia tomada de Is 61,1, subrayan aún más la vinculación. Estos beneficios que en los textos bíblicos y qumranitas tienen a Dios por autor, son efectivamente los signos que acreditan la misión del Enviado de Dios - el Hijo de Dios. Son signos que Juan no realizó, pero debían permitir a Juan y a las multitudes reconocer al mesías.

Finalmente, en los evangelios está ausente cualquier mención de los esenios, mientras que se citan muchas veces los fariseos, saduceos, herodianos y escribas. ¿Los habrían unido vínculos particulares? Herodes Antipas, que gustaba oír a Juan, lo protegía pero, por las intrigas de Herodíades a la cual Juan reprochaba sus segundas nupcias ilegítimas, no dudó en hacerlo ejecutar. ${ }^{21}$ Sobre este punto preciso Juan defendía una

${ }^{18}$ El texto no habla del "trono de Dios", a pesar de C. Evans, "Jesus and the Dead Sea Scrolls", The Dead Sea Scrolls After Fifty Years. A Comprehensive Assessment, vol. II, (ed. P. Flint - J. VanderKam - A. Álvarez), Brill - Leiden/Boston/Köln - 1999, 573-98, 582, debido a un error de traducción de M. Abegg que sigue el autor, en lugar de seguir la traducción oficial, PUECH, "521. 4QApocalypse messianique", DJD XXV, n. 17.

19 Cf. PUECH, "521. 4QApocalypse messianique", DJD XXV, 12-18: comentario detallado del pasaje y referencias.

${ }^{20}$ Mt 11,3-6 agrupa la secuencia por pares coordinados como 4Q521, mientras que LC 7,22-23 ha roto este ritmo formando dos grupos de tres, coordinados, mostrando en esto, una vez más, su trabajo redaccional sobre un sustrato semítico de una cadena conocida y recibida de la tradición. Sobre la composición de este texto, no hay ninguna influencia de la segunda bendición del šemōneh-eśrēh cuya datación también alta de ninguna manera ha sido probada.

${ }^{21}$ FLAVIO JOSEFO, Ant. XVIII $\S \S 117-119$, invoca los motivos de sublevación de las multitudes y de rebelión que subraya D. FLUSSER, "The Magnificat, the Benedictus and 
interpretación estricta de la Ley, comparable a la de los esenios y a la de Jesús. ${ }^{22}$ Flavio Josefo recuerda que los esenios eran bien vistos en el palacio por haber predicho la gloria futura de Herodes el Grande (Ant. XVII $\S \S 373-79)$ o por haber explicado un sueño de Herodes Arquelao (Ant. XVII $\S \S 346-48$ ). Y esta familia real poseía palacios en Jericó, no lejos del Jordán y ni de Qumrán. Estas cercanías y afinidades, ¿tienen algún significado?

Si bien es imposible saber si Juan conoció la Comunidad de Qumrán, en cambio es muy probable que jamás haya pertenecido a ella. No les ha tomado prestado el rito bautismal para el perdón de los pecados, ausente en su Regla. ${ }^{23}$ En este punto, el asceta Banus o los hemero-bautistas estarían más próximos a ellos. Los discípulos de Juan aparentemente no tienen nada del comportamiento esenio. Si Juan, así como los esenios, tomó distancia respecto de los diferentes judaísmos de las autoridades del Templo para volver al espíritu de la Ley, nada dice que se haya escindido del Templo donde oficiaba su padre. Predicó abiertamente a las multitudes las exigencias religiosas y morales de la Ley, administrando el único bautismo de penitencia para preparar la entrada en la era nueva, sin exclusividades o examen probatorio. Con él los tiempos mesiánicos están al alcance de la mano y no hay que esperar más. Contrariamente a las primeras tentativas que insistieron sobre los parecidos, como la preparación del Camino a partir de Is 40 (punto de partida de los dos movimientos 1QS VIII 13-16, IX 19-20, Mc 1,2-8 y

the War Scroll", Judaism and the Origins of Christianity, Magnes Press - Jerusalem 1988, 126-49, 140-45.

22 Cf. PUECH, "Manuscritos", 219-254, 222-227.

23 FluSSER, "Magnificat", 143-48, estima que Juan Bautista pertenecía al movimiento esenio en sentido amplio, y sin haber sido jamás un miembro de la comunidad, era un "esenio disidente". Jesús, por medio de él, habría tenido conocimiento de gran parte de la ética esenia. Para J. CHARLESWORTH, "John the Baptizer and the Dead Sea Scrolls", The Bible and the Dead Sea Scrolls. The Princeton Symposium on the Dead Sea Scrolls, (ed. J. Charlesworth) - The Scrolls and Christian Origins, Baylor University Press - Waco - 2006, III, 1-35, Juan Bautista habría sido un adepto esenio que no habría completado su último año de "noviciado", ya sea por haber sido expulsado por no haber pronunciado su voto definitivo de adhesión a la Comunidad, o más bien por haberla abandonado voluntariamente al meditar todas las consecuencias de semejante juramento. Así se explican ciertos comportamientos del Bautista en su vestimenta y alimentación. ¡Pero estos últimos rasgos son compartidos por otros profetas sin tener que hacer, por esto, de Juan Bautista un "esenio"! En fin, Juan Bautista habría tenido que renegar por segunda vez de la tradición de sus padres. 
paralelos), ${ }^{24}$ la urgencia de la preparación de la Visita divina, la importancia del agua y de la penitencia y la cercanía con el desierto, no se deben perder de vista las diferencias fundamentales, subrayadas más arriba. ${ }^{25}$ La partida al desierto de un grupo alrededor de un Maestro tenía como finalidad revivir la experiencia de Israel entorno a Moisés y salvaguardar así las tradiciones, viviendo en un estado de perfección para preparar, en el momento oportuno, el retorno al Templo purificado. Juan, en cambio, llama a todos sus oyentes a la conversión; el tema del desierto no ocupa allí ningún lugar particular, sin ninguna influencia qumranita directa.

\subsection{Jesús y el Maestro de Justicia}

Si en los manuscritos de Qumrán las tradiciones acerca del retorno de Elías no lo han identificado jamás con Juan Bautista, el Mesías, salvador escatológico, tampoco ha sido identificado con el Maestro de Justicia. Después del Bautismo de Juan en el Jordán, Jesús, el Galileo, se retiró al desierto donde fue tentado por el demonio. La tradición que ha situado el episodio en la región de Jericó, con las tres tentaciones que evocaban la sumisión del hombre a la doble influencia de ángeles y demonios, retoman los temas centrales de la Instrucción sobre los dos Espiritus de la Regla de la Comunidad que dominan en el corazón del hombre (IQS III 13-IV). De hecho, ciertos discípulos de Jesús fueron al principio discípulos de Juan en esa región. El Maestro galileo, ¿habría podido ser entonces el Maestro de Justicia redivivo, como se ha dicho? ${ }^{26}$

24 Cf. J. DANIÉLOU, Les manuscrits de la mer Morte et les origines du Christianisme, Orante - Paris - 1957; DuPONT-SOMMER, Écrits esséniens, 384, es más matizado.

25 J. FREY, "The Impact of the Dead Sea Scrolls on New Testament Interpretation: Proposals, Problems, and Further Perspectives", The Bible and the Dead Sea Scrolls, 407-61, 443-50, subraya muy bien estas diferencias fundamentales que militan contra la tesis de Juan Bautista personaje "esenio" o "esenisante", sea por el uso de Is 40,3 en función del estudio de la Tôrāh por un lado, o sea por el cumplimiento de la profecía de Mal 3,2 ss por el otro, o incluso por la administración del bautismo opuesto a los ritos de purificación.

${ }^{26} \mathrm{Cf}$. Dupont-Sommer, Aperçus. Pero ningún texto habla de una muerte violenta del Maestro de Justicia, ni de crucifixión, ni de resurrección, ni apariciones en el Templo. Por el contrario, la formulación del Documento de Damasco (= CD) XIX 35s: "Desde el día de la reunión (con sus padres) del Maestro de la Comunidad...", se entiende como una muerte natural del Maestro. 
En el ministerio de Jesús, el desierto no juega un rol particular y Jesús no está al frente de una comunidad estable, jerarquizada y estructurada por reglas, aunque él reivindique el título de "Maestro", didáskalos = môreh (Mc 14,14 y paralelos) y que haya construido su iglesia sobre la "roca" (Mt 16,18), palabra que evoca la fundación de la Comunidad sobre la piedra angular (1QS VIII 7-8 que retoma Is 28,16). La palabra de Jesús a Pedro "tu eres Simón, el hijo de Juan; tu te llamarás Cefas, que quiere decir Piedra" (Jn 1,42), no es nada más que un juego de palabras Kéfas - Pétros - pétra en griego. Los manuscritos de Qumrán revelan por primera vez el sentido exacto del arameo kefa' que no designa sólo una pequeña piedra como se ha pensado hasta el presente, sino también y ante todo "el peñasco" o la "roca" del Targum de Job de la gruta $11(11 \mathrm{Q} T g J b 39,28)$ donde el águila esconde su nido, "las laderas de las montañas" de las cabras montesas (11QTgJb 39,1), donde kefa' traduce el hebreo sela; o incluso "la roca elevada" sobre la que subía y se mantenía el carnero que designa Moisés en IEnoc 89,29.32 (ver también 1 Enoc 4,1). Así, no hay diferencia entre Kéfas - Pétros y pétra que puede ser incluso un topónimo: Petra, la capital nabatea en las montañas rocosas de Edom, al sur de Jordania. ${ }^{27}$ Tenemos allí uno de los ejemplos del aporte filológico de los manuscritos a la exégesis del Nuevo Testamento, ${ }^{28}$ para explicar la solidez y estabilidad de la roca sobre la cual Jesús quiere construir su Iglesia.

${ }^{27}$ Cf. J. FITZMYER, "The Meaning of the Aramaic Noun kyp'/kp' in the First Century and Its Significance for the Interpretation of Gospel Passages", 'll verbo di Dio è vivo'. Studi sul Nuevo Testamento in onore del cardinale Albert Vanhoye, S.J., (ed. J. Aguilar Chiu et al.), AnBib 165, PIB - Roma - 2007, 35-43.

28 Para un ejemplo de un aporte textual mal conocido, señalo, entre otros, la variante de 4 Samue $^{a}$ 1,[11],22 donde Ana quiere consagrar a su hijo Samuel como "nāzîr para siempre", ver Ben Sira 46,13 (manuscrito hebreo B), Flavio Josefo, Ant. V $\S 347$ (comparar § 347 para Samsón), y Mišnāh, Nedārîm IX 5. Esta tradición textual palestinense es manifiestamente citada como "Escritura profética" por Mt 2,23 (cf. Lc 4,16 , Jn 18,5.7; 19,19), que explica el juego de palabras nazareno y nazoreo (con la confusión frecuente de las waw/yod en $n z y / w r$ ) "para que se cumpla el oráculo de los profetas: 'y yo lo haré nāzîr para siempre" (4QSamª 1,11.22), título retomado todavía en el titulus crucis de Jn 19,19. Así esta lectura del Libro de Samuel es clasificada por Mateo entre los Profetas. En esta tradición se encuentra la respuesta a la pregunta planteada por el Patriarca Timoteo I cuando se produjo el descubrimiento de manuscritos al final del siglo VIII de nuestra era en una gruta de la montaña cercana a Jericó: "se encuentra en alguna parte de los profetas esto: 'Porque fue llamado nazareno'". Cf. R. Duval, "Une découverte de livres juifs à Jéricho", Revue sémitique 10 (1902) 174-79, 178. ¡Ahora finalmente conocemos la respuesta! No se puede invocar aquí un "efecto arbitrario... de un oráculo que no figura en ninguna parte en 
Jesús comió con los publicanos y los pecadores (Mc 2,16), alimentó a la multitud, ${ }^{29}$ se relacionó con el centurión romano, pagó el impuesto al César, ... mostrando con eso su apertura hacia los pecadores, hacia los excluidos del templo y hacia los no judíos, invitándolos al Reino. Pero para él "los primeros serán los últimos y los últimos los primeros", sin examen previo, sin ningún rango de ancianidad ni de precedencia, sin exclusividad como era la regla en la Comunidad (ver regla de la Comunidad y Regla de la Congregación $=1 \mathrm{QS}, 1 \mathrm{QSa}$ ).

Ciertamente, por su comportamiento y su enseñanza, Jesús está cerca de los esenios en ciertos puntos. El es un rabbî como había tantos otros en la Comunidad. y en el judaísmo de la época y tal es el sentido de la palabra en esta época en Palestina, ver rabbî - didáskalos en Jn 1,38, Mt 26,49.55, Mc 14,45.49, Lc 20,28.39, etc. ${ }^{30}$ A los discípulos enviados en misión les recomienda no llevar nada para el camino y comer lo que les ofrezcan. Y en Gestsemaní (ver Lc 22,35-38 que cita a Is 53,12), Pedro saca su espada de la vaina. Se puede comparar con lo que escribe Flavio Josefo acerca de los esenios:

\footnotetext{
.. ${ }^{125}$ Viajan sin llevar nada, salvo armas a causa de los ladrones. En cada pueblo se designa especialmente un encargado para que se haga cargo de los huéspedes, a fin de que les proporcione vestimentas y lo necesario (Guerra II $\S \S 124-25){ }^{31}$
}

En el Sermón de la montaña, Jesús manda no hacer juramentos, así como lo exige en parte el Documento de Damasco ( $C D \mathrm{XV}$ ) con la

los libros conocidos. ...el empleo del plural 'oráculo de los Profetas' deniega una citación precisa", ni afirmar que "el lugar "Nazaret' es completamente desconocido", como escribe E. NODET, "Sens littéral ou icônes? Questions", Le sens littéral des Écritures, (dir. O. Th. Venard), Lectio Divina, Cerf - Paris - 2009, 75-104, 91s. Hay restos arqueológicos bastante anteriores a esta época.

${ }^{29}$ La disposición en grupos de cien y de cincuenta retoma tanto la organización del pueblo en tiempos del éxodo (Ex 18,21.25) como la de la Comunidad (ver el Documento de Damasco [= CD] XIII 1, 1QS II 21-22, Rollo de la guerra [= 1QM] III 16IV 5, Regla de la Congregación [= 1QSa] | 14-15, 29-II 1).

${ }^{30}$ Sobre el sentido de esta palabra, ver J. CARMIGNAC, "HRBYM: les 'Nombreux' ou les 'Notables'?", RdQ 7 (1971) 575-86; S. MoraG, "On Some Concepts in the World of Qumran: Polysemy and Semantic Development", Diggers At the Well. Proceedings of a Third International Symposium on the Hebrew of the Dead Sea Scrolls and Ben Sira, (ed. T. Muraoka - J. F. Elwolde), Studies on the Texts of the Desert of Judah 36, Brill Leiden/Boston/Köln - 2000, 178-92, 186-91.

31 Es imposible saber si esta observación es exclusiva de los esenios o de los discípulos, ver Mt, 26,451-52, Mc 14,47, 22,49-50, Jn 18,10-11, o si era también un uso común en otros grupos judíos de la época. 
excepción del de la entrada en la alianza. El Maestro de Justicia dice haber recibido revelaciones divinas como un profeta para los tiempos del fin, sin embargo no fue considerado por los suyos como el Mesías, menos aun como el Servidor sufriente cuya muerte tendría un valor redentor y su vuelta no es esperada para el juicio final. Tampoco fue objeto de un culto después de su muerte. ${ }^{32}$ El Maestro con sus revelaciones pasa ciertamente por una figura profética de Israel y sus discípulos han podido, en algún momento, considerarlo como el profeta esperado. Él mandaba a los miembros estudiar constantemente la Ley y llevar a cabo "las obras de la Ley", mientras que Jesús pide a sus discípulos creer en él y seguirlo, observando ante todo el doble mandamiento del amor de Dios y del prójimo, del que derivan todos los demás y que resume toda la Ley y los Profetas (Mt 23,38-40 y paralelos).

El Maestro de Galilea, hijo de María de ascendencia aaronita, de raza davídica por José su padre adoptivo, enseñó como el nuevo Moisés y realizó signos que lo acreditaron como enviado por Dios. Condenado a la crucifixión por las más altas autoridades religiosas de su nación, muerto por la salvación de las multitudes, Dios lo ha resucitado según las Escrituras. Dotado de prerrogativas divinas en sus actos y palabras, no era esenio y los discípulos que él instruyó y envió en misión después de él, -que tampoco eran esenios- le han rendido un culto y dado el nombre de mare' - kýrios - "Señor" que la Escritura sólo reserva a Dios (ver 11QTgJb 34,12), en contraste con el simple rango de môreh - "Doctor" del Maestro en su comunidad.

Para señalar mejor los parecidos y las diferencias fundamentales entre estas dos figuras, relevemos algunos puntos importantes que conciernen a las creencias y las prácticas de los dos movimientos iniciados por estos "Maestros".

32 Sobre figuras mesiánicas antes de Jesús, ver últimamente J. J. Collins, "A Messiah before Jesus?", Christian Origins and the Dead Sea Scrolls, (ed. J. J. Collins - C. A. Evans), Baker Academic - Grand Rapids - 2006, 15-35, y también una puesta a punto sobre "An Essene Messiah? Comments on Israel Knohl, The Messiah before Jesus", idem., 37-44. 


\section{Las creencias}

Herederos de la tradición pietista de los asideos, no es sorprendente que esenios y fariseos hayan compartido las mismas creencias en temas centrales de la reflexión de los profetas después del enorme trauma del exilio, a saber, la restauración de la monarquía y la responsabilidad individual y colectiva, frente a la promesa y la justicia divina que jamás pueden fallar. Dos puntos focalizan esta visión de un futuro más o menos inmediato o escatológico: el mesianismo, y las recompensas y castigos después de la muerte.

\subsection{El mesianismo}

La reanudación del culto en el templo y el restablecimiento de la monarquía davídica están en el origen de un mesianismo bicéfalo o diárquico del cual se encuentran rastros en Jeremías, Ezequiel, Zacarías, Daniel y las Crónicas, como también en los apócrifos. Esta concepción, todavía en vigor en el siglo II de nuestra era, en el medio rabínico con el par Eleazar-Bar Kokbah, “el príncipe de Israel”, está íntimamente ligada a la venida del profeta, Nuevo Elías.

Habiendo recibido esta concepción de textos tradicionales, los esenios la formularon varias veces mandando a sus miembros que se ajustaran a los reglamentos en vigor "hasta la venida del Profeta y de los Mesías de Aarón y de Israel" (1QS IX 11, CD XIX 10-11). En la comida comunitaria (1QSa II $11 \mathrm{ss}$ ), el mesías sacerdote tendrá la precedencia sobre el mesías rey, "príncipe de la congregación, retoño de David". Su venida debía inaugurar una época nueva aportando a Israel la victoria sobre los impíos y sobre las naciones. Esta concepción que no ha variado en las diversas composiciones $(1 \mathrm{Q} S, 1 \mathrm{QS} a, 1 \mathrm{Q} M[$ ilhamah = Regla de la guerra], CD, los Testimonia [=4Q175], el Comentario del Génesis ${ }^{a}$ [4Q252], etc.), ${ }^{33}$ debió encontrar un terreno abonado en su reacción

33 Cf. E. PUECH, "Mesianismo, escatología y resurrección en los manuscritos del Mar Muerto", Paganos, judíos y cristianos en los textos de Qumrán, (coord. J. Trebolle Barrera), Biblioteca de Ciencias Bíblicas y Orientales 5, Trotta - Madrid - 1999, 245-86, 254-75, (con la bibliografía), sin poder seguir en todos los puntos a F. GARCía MARTíneZ, "Esperanzas mesiánicas en los escritos de Qumrán", Los Hombres de Qumrán. Literatura, estructura social y concepciones religiosas, F. García Martínez - J. Trebolle Barrera, Trotta - Madrid - 1993, 187-222 y J. STARCKY, "Les quatre étapes du messianisme à Qumrân", RB 70 (1963) 481-505. 
contra la dinastía asmonea, no davídica, que ilegítimamente, según su manera de ver, había acaparado y reunido los dos poderes bajo un solo jefe. El exilio del Maestro, sumo sacerdote legítimo en 152 a.C. no podía sino reforzar su lectura de los textos bíblicos y sus prerrogativas sadocitas.

Según sus cálculos, el Maestro, que vivía en el anteúltimo jubileo, pudo ser considerado, al menos por algunos de sus discípulos, como el Profeta esperado, que daba la interpretación auténtica de la Ley y anunciaba la venida inminente del Mesías. El Apocalipsis mesiánico (= 4Q521) se expresaría en este sentido. ${ }^{34}$ Pero en 11QMelquisedec no se puede hablar de mesías celeste, sino por analogía, siendo Melquisedec una figura escatológica. ${ }^{35}$ Tampoco se puede hablar de mesías colectivo en el Apócrifo de Daniel (=4Q246) que anuncia, a su manera, la figura del Hijo del Hombre que viene en las nubes del cielo en Daniel 7, pasaje donde Renan veía la última esperanza mesiánica. ${ }^{36} \mathrm{El}$ manuscrito arameo Apócrifo de Daniel contiene la única referencia a la venida de un personaje con quien todos los reyes harán la paz y le servirán, 4Q246 1 i 9-ii 9:

¡el hijo del gr]ande [soberano] será llamado y por su nombre será nombrado, ii'será dicho Hijo de Dios e Hijo del Altísimo se lo llamará ... ${ }^{2} \ldots{ }^{5}$ Su reino es un reino eterno... Juzgará ${ }^{6}$ la tierra en la verdad... ${ }^{7} . .$. el gran Dios es él mismo su fuerza. ${ }^{8} \ldots{ }^{9} \ldots$ y su dominación es una dominación eterna, y todos los abismos $\left[\ldots{ }^{37}\right.$

${ }^{34}$ Cf. PUECH, "521. 4QApocalypse messianique", DJD XXV. Los fragmentos 4Q521 $2+4$ iii tratan claramente del Profeta precursor y del mesías rey. Pero en la columna 2+4 ii 1-3, el mesías del cual se trataba entonces, puede ser el Sacerdote que cumplía también una misión profética, como es el caso en Is 61,1-3; el sacerdocio es incluso mencionado en otros fragmentos de este manuscrito.

${ }^{35}$ Para una presentación del personaje y del Rollo Melquisedec ver E. PUECH, "La figure de Melkîsedeq et la fin des temps (11QMelk-4Q180-181-4QVis'Amr-4QTestQah4Q280-286-287", La croyance des Esséniens en la vie Future. Histoire d'une croyance dans le Judaïsme ancien, Les données qumraniennes et classiques, Études Bibliques, Nouvelle Série 22, Gabalda - Paris - 1993, II, 515-62. Melquisedec es también otro nombre de Miguel (ver las Visiones de Amram - 4Q543-547), agente ejecutor del oráculo de salvación, que preside sobre el pueblo de Dios (ver Dn 12,1), pero como figura angélica, no es un mesías o un ungido, ver Heb 1,5-14. O él cumple entonces la función de rey-sacerdote celeste.

${ }^{36}$ Cf. E. Renan, Histoire des origines du Christianisme. Vie de Jésus, les Apôtres, Saint Paul - Lafont - Paris - 1995; Vie de Jésus, 80.167s.

37 Para la editio princeps, ver E. PUECH, "246. 4QApocryphe de Daniel ar", Qumran Cave 4 XVII. Parabiblical Texts, Part 3, (G. Brooke et al.), DJD XXII, Clarendon 
Estas líneas no podrían designar a ningún otro que al rey mesías ${ }^{38} \mathrm{y}$ esas mismas designaciones se encuentran textualmente en el relato de la Anunciación en Lc 1,32-35:

\begin{abstract}
${ }^{32}$ será grande y se lo llamará Hijo del Altísimo. El Señor Dios le dará el trono de David, su padre. ${ }^{33}$ Reinará sobre la Casa de Jacob para siempre y su reino no tendrá fin. ${ }^{34}{ }^{35} \ldots$ será llamado Hijo de Dios.
\end{abstract}

Pero si bien este texto prequmranita era conocido en el judaísmo palestinense, en los manuscritos, en cambio, no hay nada del mesías engendrado por Dios, ${ }^{39}$ ni de un mesianismo soteriológico con una muerte sacrificial del mesías para expiar los pecados del pueblo, como algunos lo han escrito. ${ }^{40}$ Esta interpretación del Siervo sufriente propia del Nuevo Testamento está ausente en corrientes judías. Dios solo perdona los pecados. ${ }^{41}$ La Comunidad se comprometía a "practicar la justicia, y una

Press - Oxford - 1996, 165-84, pero para una interpretación puesta al día con bibliografía ver E. PUECH, "Le fils de Dieu, le fils du Très-Haut, messie roi en 4Q246", Le jugement dans l'un et l'autre Testament, I - Mélanges offerts à Raymond Kuntzmann, textes réunis par E. Bons, Lectio Divina 197, Cerf - Paris - 2004, 271-86, donde entre las dos soluciones posibles, yo mantengo mi primera sugerencia de mesías rey que, únicamente, se ajusta a este pasaje, sin entrever un "libertador escatológico de naturaleza angélica", de GARCíA MARTíneZ, "Esperanzas mesiánicas", 205-208. Igualmente, los títulos no pueden remitirnos al pueblo de Dios bajo forma de figura mesiánica corporativa, como lo escribe A. PIÑERO, "Los manuscritos del mar Muerto y el Nuevo Testamento", Paganos, judíos y cristianos, 287-317, 303.

38 En este pasaje con lagunas, nada permite decir si ese rey mesías, figura escatológica, es un ser celeste, Hijo de Dios (no un ángel), pero los títulos no se opondrían y remiten claramente al Hijo del Hombre de Daniel 7, que viene en las nubes del cielo, recibe gloria y realeza eterna ante el trono divino, y a "Tu eres mi hijo, yo te he engendrado hoy ..." del Sal 2,2.7-9 a propósito del rey mesías, y a 2 Sam 7,14 .

39 Como lo recuerda incluso García Martínez, "Esperanzas mesiánicas", 211s.; cf. E. PUECH, "Préséance sacerdotale et Messie-Roi dans la Règle de la Congrégation (1QSa II 11-12)", RdQ 63 (1994) 351-365, pero leyendo "cuando e[I prí]n[cipe mesías ]se unirá a ellos, [el sacerdote] entrará a la cabeza de..." (rectifico mi lectura de entonces "será revelado" y explicaré esto en otro lugar).

${ }^{40}$ Así R. H. EISENMANN - M. O. WISE, The Dead Sea Scrolls Uncovered, Shaftesbury - Rockport - 1992, 24-29; cf. P. S. AlEXANDER, "A Reconstruction and Reading of 4Q285 (4QSefer ha-Milhamah)", RdQ 75 (2000) 333-348.

${ }^{41}$ Cf. E. PUECH, "La prière de Nabonide (4Q242)", Targumic and Cognate Studies. Essays in Honour of Martin McNamara, (ed. K. J. Cathcart - M. Maher) JSOT.S 230, Sheffield Academic Press - Sheffield - 1996, 208-27, 216-19, con una puesta a punto sobre el tema. Además, Jesús perdona los pecados en su calidad de Mesías-Hijo de Dios, pero no obra como simple exorcista o taumaturgo judío. Ver también, en este sentido, G. GUTTENBERGER, Die Gottesvorstellung in Markusevangelium, BZNW 123, De Gruyter - Berlin - 2004, 288-93. No se puede sostener la interpretación de F. GARCíA 
caridad condescendiente, a expiar los extravíos ... y a obtener el perdón en favor del país" (1QS VIII 1-7). Pero la expiación definitiva es esperada por Melquisedec mismo en el último kîppûr del último jubileo (ver 11QMelquisedec).

En tal expectativa mesiánica, preparada por la predicación de Juan Bautista que debía designarlo públicamente, tuvieron lugar la encarnación y la manifestación del Mesías Jesús el Nazoreo/Nazareno, ${ }^{42}$ anunciada por los profetas. Jesús realiza en su persona la figura del rey Mesías del Anuncio del ángel Gabriel, como lo han revelado sus hechos, gestos y enseñanza que le valieron la condena a muerte en la cruz, bajo la doble acusación de blasfemo y "Rey de los Judíos", 43 y donde la figura del Mesías sacerdote se ofrece como víctima sacrificial de la Alianza nueva y eterna. También la Carta a los Hebreos puede jugar con la figura del rey-sacerdote Melquisedec, ${ }^{44}$ y los evangelios de la infancia, en Mateo especifican el nacimiento de Jesús en Belén como hijo de David, y en Lucas el parentesco de María con Isabel descendiente de Aarón. Así, a los ojos de sus contemporáneos, Jesús a quien Juan Bautista designó como el Cordero de Dios, como prefiguración del cordero inmolado, cumplía todas las Escrituras, lo que no se dice jamás del Maestro de Justicia, jamás identificado con el Siervo sufriente, ni entronizado en los cielos, como el Hijo del Hombre resucitado, y del cual ningún texto dice esperar su vuelta para el juicio final. Si bien esenismo y cristianismo son productos de una misma cultura, en una misma región y con las mismas expectativas en el punto de partida, el Maestro no es sino un intérprete,

Martínez, "Magic in the Dead Sea Scrolls", The Metamorphosis of Magic from Late Antiquity to the Early Modern Period, (ed. J. Bremmer - J. R. Weenstra), GSCC 1, Peeters - Leuven - 2002, 13-33, para quien el exorcista perdona los pecados, según una lectura defectuosa y una interpretación errónea del pasaje.

${ }^{42}$ Ver más arriba la nota 28.

${ }^{43}$ Cf. PUECH, "Manuscritos", 219-254, 243-248.

${ }^{44} \mathrm{El}$ rollo $11 \mathrm{QMelquisedec} \mathrm{es} \mathrm{el} \mathrm{único} \mathrm{texto} \mathrm{donde} \mathrm{está} \mathrm{ampliamente} \mathrm{precisado} \mathrm{el}$ rol escatológico de esta figura como juez y sacerdote eterno, y el autor de la Carta a los Hebreos que lo considera como sumo sacerdote eterno y víctima, como profeta superior a Moisés e Hijo de David, como Hijo de Dios $(7,3)$, supone conocido este género de literatura y un método exegético similar. Los "Hebreos" en cuestión a quien era dirigida la Carta, ¿no serían los esenios convertidos, único grupo judío de la época capaz de comprender semejante figura comparativa y profecía realizada? En efecto, el hebreo era "la lengua del santuario" y la lengua principal de composición, empleada también en la vida cotidiana, como lo prueban los ostraca y algunas inscripciones descubiertas en el lugar. 
ciertamente autorizado, de las Escrituras, mientras que Jesús, nuevo Moisés, ha revelado el espíritu cumpliendo el designio divino.

\subsection{La vida futura: resurrección, recompensas y castigos}

Esenios y fariseos profesaban la misma visión del más allá que sus predecesores, como lo testimonian pasajes de libros proféticos y sapienciales, los Apócrifos prequmranitas, como el Pseudo-Ezequiel (4Q385 2 // 3861 i // 388 7), la Instrucción (4Q418 69), IEnoc, ${ }^{45} \mathrm{o}$ composiciones qumranitas como el Apocalipsis mesiánico (4Q521), la Instrucción sobre los dos Espiritus de la Regla de la Comunidad (1QS III-IV) o Himnos (1QHa) ${ }^{46}$ En estos ambientes piadosos, la resurrección de los muertos en los tiempos escatológicos del Juicio, en tanto que recompensa, no concernía sino a los justos de Israel que debían revestir la gloria del Adán inmortal, como un retorno al paraíso de los orígenes,

45 Ver 1 Enoc 24-25 del Libro de los Vigilantes, 90,33 del Libro de los Sueños, y 91,8-10; 103,4 y 104,2.4.6 de la Carta de Enoc, datados del siglo III o de la primera mitad del siglo II a.C.

46 Cf. E. PUECH, La croyance des Esséniens en la vie future: immortalité, résurrection, vie éternelle? Histoire d'une croyance dans le judaïsme ancien, I: La résurrection des morts et le contexte scripturaire, II: Les données qumraniennes et classiques, Études Bibliques Nouvelle Série 21-22, Gabalda - Paris - 1993, passim. Contrariamente a lo que se me adjudica todavía A. L. A. Hogeterp, "Belief in Resurrection and Its Religious Settings in Qumran and the New Testament", Echoes from the Caves: Qumran and the New Testament, (ed. F. García Martínez), Studies on the Texts of the Desert of Judah 85, Brill - Leiden/Boston - 2009, 299-320, 300, no he considerado las Visiones de 'Amram como una composición esenia (ver vol. 2, 532) y he dejado abierta la discusión sobre el origen del Pseudo-Ezequiel (ver vol. 2, 605s). En contraposición, sigo estimando (vol. 2, 664-69) el Apocalipsis mesiánico (4Q521) como una composición esenia: 1) ausencia del tetragrama reemplazado por el sustituto 'dny en todas las citaciones bíblicas como se da en el rollo de los Himnos por ejemplo y contrariamente al Pseudo-Ezequiel, lo que la hace una composición posterior a 150 y sin duda de la segunda mitad del siglo II a.C. en acuerdo con las indicaciones paleográficas, 2) la mención de pobres, piadosos, fieles, humildes, santos, justos, típico del vocabulario esenio como también otras expresiones muy qumranitas "obra buena"..., 3) las recomendaciones de un maestro a sus discípulos, y 4) su presencia única en Qumrán sugieren firmemente una pertenencia al corpus esenio. No se espera la presencia de un vocabulario limitado y esteriotipado en cada línea de un texto como prueba de una pertenencia a ese corpus, como lo reclama toda una corriente actual de investigación. El móvil, a veces no confesado, de este rechazo es la contradicción de la noticia de Flavio Josefo (Guerra II §§ 154-158) que atribuye falsamente la creencia griega de la inmortalidad del alma, y no la resurrección del cuerpo, a los semitas esenios con una apocalíptica tan marcada y tan extraña al medio griego (ver vol. 2, 703-69). 
mientras que el castigo de los impíos consistía en permanecer en la muerte y la perdición eternas.

Esta es la creencia que retoman y resumen al pasar Dn 12,2-3 y 2Mac 7,14, y que es un poco más explícita en el Apocalipsis mesiánico 4Q521, y es también lo que enseña "el Maestro" Jesús. Respondiendo a los saduceos, que niegan la creencia en la resurrección, Jesús declara que el justo resucitado será "como los ángeles" y de esa manera afirma que la resurrección de los muertos, al final de los días, no es una vuelta a la vida anterior donde se toma mujer o marido, sino que para los que sean juzgados dignos de tener parte en el otro mundo y en la resurrección de los muertos, será una vida gloriosa en Dios, en compañía de los ángeles (Lc 20,27-38). El Nuevo Testamento conoce a la vez la sola resurrección de los justos (Lc 14,14; 20,34-36; como Daniel 12 hebreo y los manuscritos del mar Muerto) y la resurrección general (Mt 25,32 ss) y la restauración universal (Hech 3,21), retomando imágenes de los Himnos de Qumrán (1Q $H^{\mathrm{a}}$ XI 20-37) sobre la Conflagración (ekpýrōsis) y la Renovación universal de los cielos y de la tierra, concebida como una nueva creación (liberada del pecado y de los impíos) y una vuelta al paraíso de los orígenes del hombre imagen de Dios, que vive en su presencia y en compañía de los ángeles. El Nuevo Testamento refleja en esto la evolución de esta creencia entre la etapa prequmranita por un lado, y la qumranita y la transmitida por Daniel 12 (griego) por otro.

Así, el texto más claro, el manuscrito Apocalipsis mesiánico (4Q521 fragmentos 7+5 ii) describe la creencia en la resurrección de los justos, bajo la forma de un credo, como una nueva creación por Dios en el momento del juicio y de la recompensa escatológica: así como Él creó el cielo, la tierra y el mar y todo lo que contienen, así juzgará y resucitará a los justos de su pueblo: en el día del Juicio, los malditos, vivos o muertos, serán destinados a la muerte y los castigos eternos, mientras que los justos que hayan muerto resucitarán para la vida eterna, y los vivientes serán transformados en gloria. Cuando se renueven todas las cosas, Dios creará nuevamente, resucitando a los justos o transformándolos en gloria, los ángeles vendrán a su encuentro, mientras que los malditos caerán rígidos en el Abismo de fuego, en el pasaje del "puente del Abismo" (gešer t'hôm). Es la primera y única mención en hebreo de semejante puente que retoma la imagen del "puente del que elige" (peretu Činvato) del zoroastrismo persa, en un pasaje de estilo poético (4Q521 7+5 ii 1-15) que yo entiendo así: 
1 ...]miren todo lo q[ue ha hecho ${ }^{2}$ el Señor:

la tier]ra y todo lo que contiene,

los mares [y todo ${ }^{3}$ lo que contienen]

y las extensiones de las aguas y los torrentes. vacat

${ }^{4}$ [Ustedes se regocijarán, ustedes to]dos que hacen el bien delante del Seño[r,

${ }^{5}$ los benditos y $\mathrm{n}$ ] o como aquellos, los maldit[os,] porque serán para la muerte,

[mientras] ${ }^{6}$ el vivificador re[sucitará] a los muertos de su pueblo. vacat

${ }^{7} Y$ nosotros daremos gracias y les anunciaremos las justicias del Señor

que [ha librado (?) $]^{8}$ a los mortales y ha abierto[ las tumbas de los justos/de los muertos de su pueblo]

${ }^{9} \mathrm{y}$ [el ángel] a[brió los libros donde están inscritas las obras de cada uno(?)]

${ }^{10} \mathrm{y}$ [ el Señor se sentará en su trono (de gloria) para el juicio (universal/de todas sus obras)(?)]

${ }^{11} \mathrm{y}$ el valle de la muerte [estaba] r[epleto(?) de una multitud de hombres/de muertos que él dió(?)]

${ }^{12} \mathrm{y}$ el puente del [gran] Abis[mo ha sido establecido para su cruce (?), de tal suerte que]

${ }^{13}$ se han cuajado los maldit[os en las profundidades del sheol infernal, ]

${ }^{14}$ pero se han adelantado(a)s a los cielos [ las (almas de los) justos/benditos en la gloria eterna (?)

${ }^{15} \mathrm{y}$ to]dos los ángeles[ bendecirán al Señor que ha hecho justicia a cada uno(?)..."

Muchas de estas imágenes y conceptos se encuentran en distintos pasajes del Nuevo Testamento, evangelios y cartas paulinas (ver por ejemplo 1 Tes 4,13-18; 5,9-10; 2 Tes $1,6-10$; 1 Cor 15 ; 2 Cor $5,1-10){ }^{47}$

Estas creencias sobre los fines últimos y la vida del justo con Dios en compañía de los ángeles, suponen una especulación desarrollada sobre los buenos y malos ángeles, atestiguada e incluso central en los manuscritos del Mar Muerto. Los asideos o "piadosos", y más tarde los

47 Un pasaje mal conservado de 4Q548 (= Visión de 'Amram ?) 1-2 ii 12-14 parece haber sido leído así: "12...Porque todos los hijos de la luz] ${ }^{13}$ y a la luz para ser marcados para [la vida eterna, en el gran] juicio [irá]n, y todos los hijos de las tinie[blas a las tinieblas, a la muerte] ${ }^{14} \mathrm{y}$ al abandono irán." Yo corrijo el desciframiento de una palabra parcialmente conservada en la línea 13 y restauro en consecuencia, ver Ez 9,4.6 et Ap 7,2-3 donde los elegidos "están marcados en la frente" con el sello (la taw paleo-hebrea es una marca en forma de cruz); cf. E. PUECH, Qumrân Grotte 4 XXII. Textes araméens, Première partie 4Q529-549, DJD XXXI, Clarendon Press - Oxford 2001, 394-97. Esta precisión subraya siempre que la resurrección y la salvación eternas son reservadas a los justos del pueblo de Dios. Pero no se puede aceptar la lectura de Hogeterp, "Belief", para la línea 13. 
esenios y fariseos, han recibido estas creencias de la tradición y se las han apropiado. Esto está supuesto en el inciso en Hech 23,8:

En efecto, los saduceos dicen que no hay resurrección, ni ángeles ni espíritus, mientras que los fariseos profesan una cosa y la otra (tà amfótera).

Esto se entiende de la resurrección o transformación en gloria del justo que no es concebida como un retorno a la vida en la tierra, sino como la recuperación del estado del nuevo Adán devenido inmortal, creado a imagen de Dios y viviendo en compañía de los ángeles en el Paraíso. Es la transformación en gloria de la visión beatífica en la cual viven actualmente Moisés y Elías que conversaban con Jesús en la Transfiguración sobre la montaña alta. Ellos que fueron llevados al cielo, gozan en actualidad de la visión de la faz de Dios a rostro descubierto, contrariamente a sus experiencias en el Sinaí-Horeb (Mc 9,2-8 y paralelos). ${ }^{48}$ Así se comprende perfectamente la respuesta de Jesús a los saduceos (Mc 12,18-27 y paralelos), y pasajes de las cartas (1 Ts 4,13-18; 5,1-11, 2 Ts 1,5-10 y 1Co 15) que suponen la creencia en la existencia de ángeles y de espíritus o cuerpos espirituales. ${ }^{49}$

Así, los esenios como el Nuevo Testamento han comprendido la resurrección no como una participación en el reino mesiánico en una vuelta a la tierra, sino como la entrada en la vida y la paz escatológica, cuando se produzcan la renovación de los cielos y la tierra y el juicio final que presidirán Dios y su Mesías. Pero el Nuevo Testamento confiesa ya las primicias de la nueva creación en la resurrección del Mesías Jesús, glorificado y sentado a la derecha del Padre.

${ }^{48}$ Ver últimamente M. GILBERT, "Why Moses and Elijah at the Transfiguration?", Rivista Biblica 65 (2009) 217-22, 221, sin embargo la tradición judía de una vuelta de Elías como precursor del Mesías es bastante anterior a los inicios del cristianismo, ver los manuscritos 4Q521 fragmento 2 iii 1-7 y 4Q558 fragmento 51 ii 4-5, aun cuando Mateo y Marcos no vislumbran la vuelta de Elías como precursor del Mesías Jesús.

${ }^{49}$ Ver mi última puesta a punto en E. PUECH, "Apports des manuscrits de Qumrân à la croyance à la résurrection dans le Judaïsme ancien", Qoumrân et le Judaïsme au tournant de notre ère, Actes de la Table Ronde, Collège de France, 16 novembre 2004, (dir. A. Lemaire - S. Mimouni), Collection de la Revue des Études juives, Peeters Paris/Louvain/Dudley - 2006, 81-110; O ID., "Resurrection: the Bible and Qumran", The Bible and the Dead Sea Scrolls. The Princeton Symposium on the Dead Sea Scrolls, The Bible and the Qumran Community, (ed. J. Charlesworth), Baylor University Press Waco - 2006, II, 247-81. 
En conclusión, los manuscritos del Mar Muerto que no han sido escritos por y para cristianos, no han revelado pertenencia de Juan ni de Jesús al movimiento esenio, aunque uno y otro hayan encontrado esenios principalmente durante sus desplazamientos en Judea, Jerusalén y sus alrededores. Sin embargo, estos manuscritos nos hacen conocer desde el interior el modo de vida y las creencias de una corriente del judaísmo hasta ahora sólo conocida por fuentes externas, ${ }^{50}$ revelando en eso mismo los rostros de judaísmos diferentes en la época del comienzo de la era cristiana. Varios textos esclarecen pasajes de los evangelios por palabras, expresiones, conceptos idénticos o muy parecidos en las lenguas locales, hebreo y arameo ahora mejor conocidos, más próximos a lo que están los libros bíblicos más antiguos. Sobre ciertos puntos pueden servir de eslabón perdido mostrando las raíces del mensaje evangélico en los hechos, gestos y palabras de Jesús, en el sentido de que tal o cual creencia, esperanza o también palabras traducidas en griego tienen correspondencias exactas en los manuscritos, en esa época, en esa misma región.

No obstante, al convertir en caducas las explicaciones que han dado ciertos eruditos de los hechos o logia de Jesús sobre un trasfondo de filosofía greco-romana, estos nuevos datos no hacen por eso de Jesús, el nazoreo/nazareno y Maestro de Galilea, un esenio ni una pálida figura reencarnada, el Maestro de Justicia redivivo. En ninguna parte se dice del Maestro de Justicia que sea el Mesías, ni es presentado como el Mesías sufriente para la expiación de los pecados y la salvación del mundo. $\mathrm{Su}$ muerte no tuvo valor redentor: él fue a encontrarse con sus padres, es decir murió de una muerte natural, como lo recuerda el Documento de Damasco (CD XIX 35 - XX 1), mientras que este es el mensaje central del kērygma pascual: Jesús, muerto y resucitado, Cristo y Señor, de quien los creyentes esperan su vuelta como juez escatológico de vivos y muertos; Jesús a la vez rey, Hijo de David, rey de los judíos; y sacerdote de la descendencia de Aarón por María su madre. Esta última función es aun significada, a la manera de un comentario tipológico esenio, por la precisión sobre la túnica inconsútil tejida de una sola pieza en Jn 19,2324, como la vestimenta del sumo sacerdote en Ex 28,32. Con Jesús, ha llegado el Mesías, el Reino de Dios está presente y no hay nada más que

50 Principalmente Flavo Josefo, Plinio el Viejo, Hipólito de Roma y Filón de Alejandría. 
esperar, mientras que la Comunidad de Qumrán estimaba vivir en las últimas generaciones antes de la venida del final de los tiempos y de los dos mesías, el sacerdote y el rey, el sacerdote teniendo precedencia y el rey la preeminencia. Con él, las Escrituras han llegado ya a su culminación. Jesús ha revelado su sentido profundo y ha dado la clave cumpliéndolas (Lc 24,13-35).

ÉMILE PUECH

PARIS - JERUSALEM

emile.puech@gmail.com 